\title{
Constraint Effect by Strength Mis-Matching and Its Application to $K_{\mathrm{IC}}$-Measurement
}

\author{
by Mohamed El-Shennawy* Member \\ Masao Toyoda* Member \\ Masanao Fujii**
}

\author{
Fumiyoshi Minami* Member \\ Katsuya Kajimoto** Member \\ Ryosuke Murai** Member
}

\begin{abstract}
Summary
The application of Laser welds close to the notch of toughness specimen was made to create a highconstrained condition near the notch tip. Laser welds enabled a very thin specimen (thickness, $B=2.5$ $\mathrm{mm})$ to promote brittle fracture at a lower CTOD level than the full-thickness $(B=20 \mathrm{~mm})$ homogeneous specimen. This is due to the plastic constraint induced by the strength mis-matching. Controlling factors for the plastic constraint were addressed by $3 \mathrm{D} \mathrm{FE}$-analysis. It was pointed out that the location of Laser welds (distance from Laser welds to the notch) and the shape of Laser welds give a marked effect on the plastic constraint around the notch. By contrast, the influence of the width of Laser welds was marginal. By using strength mis-matching effect, the thickness requirement for $K_{\mathrm{IC}^{-}}$ measurement could be reduced to a large extent.
\end{abstract}

\section{Introduction}

This paper discusses the applicability of small size specimen to $K_{\mathrm{IC}}-$ measurement using strength mis-matching effect.

Strength mis-matching effect on fracture toughness and fracture behavior has been investigated by many researches ${ }^{1) \sim 6 \text { ) }}$. Strength mis-matching brings about the plastic constraint which plays an important role in decreasing fracture resistance of materials with lower toughness ${ }^{1,4) \sim 6}$. On the other hand, the plastic constraint is affected by geometrical parameters ${ }^{\text {7) 9) }}$ such as crack size, plate thickness and structural discontinuity. However, the degree of plastic constraint by geometrical factors is limited to a certain level. It has been shown $^{10)}$ that the use of side groove is not always effective to activate the crack tip stress field.

This study aims at discussing the use of strength mismatching in $K_{\mathrm{IC}}$-measurement in terms of plastic constraint effect. A couple of Laser welds were applied to create large plastic constraint in the crack-tip region. Notch was located in the middle region between the two Laser welds. Three-dimensional finite element analysis was conducted to investigate the stress/strain behavior at the crack-tip region surrounded by the Laser welds. FE-analysis focuses on controlling factors of plastic constraint. The distance from the notch plane to Laser

* Department of Welding \& Production Engineering, Faculty of Engineering, Osaka University

** Hiroshima Research \& Development Center, Mitsubishi Heavy Industries, Ltd.

Received 10th Jan. 1995

Read at the Spring meeting 17, 18th May 1995 welds, the width of Laser welds and the shape of Laser welds were considered. The condition for getting highly -constrained state was discussed in the light of $K_{\mathrm{IC}^{-}}$ measurement.

\section{Experiments}

Three-point bend specimens were extracted from a long-term used $20 \mathrm{~mm}$ thick pressure vessel of a chemical plant. Material of the pressure vessel was a $\mathrm{C}-1 / 2$ Mo steel of ASTM A 204 A class. The chemical composition and mechanical properties of the material extracted from the long-term used vessel are shown in Table 1. The yield strength and tensile strength met the value specified in the standard, while the impact energy showed a decrease by about $15 \mathrm{~J}$ from the standard value. This loss in the impact energy resulted from the embrittlement by long-term usage.

The size of the test specimen extracted from the pressure vessel in service should be as small as possible to keep the structural integrity of the pressure vessel. In this study 2.5 and $5 \mathrm{~mm}$ thick specimens were extracted. As a reference specimen, the full-thickness $(B=20$ $\mathrm{mm}$ ) specimen was also used.

A couple of Laser welds were laid for thin specimens $(B=2.5,5 \mathrm{~mm})$ as shown in Fig. 1 . The distance (e )

Table 1 Chemical composition and mechanical properties of A 204 A steel.

\begin{tabular}{l|c|c|c|c|c|c|c|c|c|c|}
\hline & \multicolumn{3}{|c|}{ Chemical composition (mass \%) } & \multicolumn{3}{c|}{ Mechanical properties } & $\begin{array}{c}\mathrm{VE} \\
\text { at }\end{array}$ \\
\hline & $\mathrm{C}$ & $\mathrm{Si}$ & $\mathrm{Mn}$ & $\mathrm{Mo}$ & $\mathrm{S}$ & $\mathrm{P}$ & $\begin{array}{c}\sigma_{\mathrm{Y}} \\
(\mathrm{MPa})\end{array}$ & $\begin{array}{c}\sigma_{\mathrm{T}} \\
(\mathrm{MPa})\end{array}$ & $\begin{array}{c}\varepsilon_{\mathrm{T}} \\
\%\end{array}$ & $\begin{array}{c}\text { at } \\
(\mathrm{J})\end{array}$ \\
\hline $\begin{array}{c}\text { A204A } \\
\text { steel }\end{array}$ & 0.15 & 0.25 & 0.80 & 0.55 & 0.035 & 0.030 & 395 & 549 & 14 & 14.7 \\
\hline
\end{tabular}
$\sigma_{\mathrm{Y}}$ : Yield strength (lower yield point), $\sigma_{\mathrm{T}}:$ Ultimate tensile strength
$\varepsilon_{\mathrm{T}}$ : Uniform elongation in G.L. $=50 \mathrm{~mm}$, Dia. $=12.5 \mathrm{~mm}$


from the notch plane to the weld center was varied as indicated in Table 2. Figure 2 exhibits the hardness distribution at the weld cross section. Laser welds bring very hard zones (about 2.5 times hardness compared with the base metal) near the notch. It is pointed out, however, that the hardness and microstructure of the

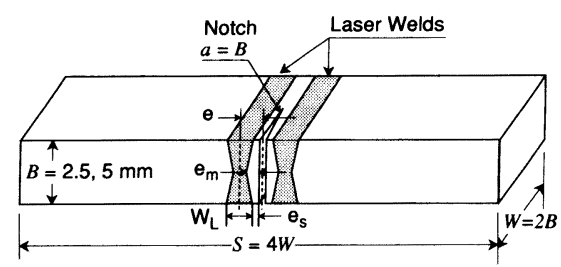

Fig. 1 Configuration of 3-point bend specimen with Laser welds.

Table 2 Three-point bend specimens used in experiments.

\begin{tabular}{|c|c|c|c|c|c|c|}
\hline \multirow{2}{*}{\multicolumn{2}{|c|}{ Dimension }} & \multirow{2}{*}{$\begin{array}{c}\text { Distance } \\
\theta \\
(\mathrm{mm})\end{array}$} & \multicolumn{3}{|c|}{ Fracture toughness ${ }^{*}$} & \multirow{3}{*}{\begin{tabular}{|l|} 
Symbol \\
B2.5 \\
\end{tabular}} \\
\hline & & & $\underset{\left(M N / m^{3 / 2}\right)}{K_{a t}}$ & $\begin{array}{c}\delta_{\mathrm{cr}} \\
(\mathrm{mm})\end{array}$ & $\delta_{c} / \delta_{c t}^{20}$ & \\
\hline \multirow{3}{*}{$2.5 \times 5$} & $\begin{array}{l}\text { Homogeneous } \\
\text { specimen }\end{array}$ & 一 & 170 & 0.153 & 4.25 & \\
\hline & \multirow{2}{*}{ With Laser welds } & 1.0 & 62 & 0.023 & 0.64 & B2.5e1.0 \\
\hline & & 1.5 & 139 & 0.109 & 3.03 & $B 2.5 e 1.5$ \\
\hline \multirow{4}{*}{$5 \times 10$} & \multirow{2}{*}{$\begin{array}{l}\text { Homogeneous } \\
\text { specimen }\end{array}$} & - & 108 & 0.089 & 2.47 & \multirow{2}{*}{ B5 } \\
\hline & & - & 171 & 0.223 & 6.19 & \\
\hline & \multirow{2}{*}{ With Laser welds } & 1.5 & 54 & 0.023 & 0.64 & $\mathrm{~B} 5 \mathrm{e} 1.5$ \\
\hline & & 2.5 & 84 & 0.064 & 1.78 & $85 e 2.5$ \\
\hline \multirow{2}{*}{$20 \times 40$} & \multirow{2}{*}{$\begin{array}{c}\text { Homogeneneus } \\
\text { specimen }\end{array}$} & 一 & 55 & 0.036 & 1.00 & \multirow{2}{*}{$\mathrm{B} 20$} \\
\hline & & - & 62 & 0.036 & 1.00 & \\
\hline
\end{tabular}

crack-tip region were almost the same as those of the base metal, as shown in Figs. 2 and 3, respectively.

Residual stresses due to welding were about \pm 100 $\mathrm{MPa}$ in the transverse direction of the weld. The effect of residual stress is expected to be small because the notch is parallel to the welds.

The fracture toughness test was carried out based on ASTM E 399-83 ${ }^{11)}$ at room temperature. K (stress intensity factor) and CTOD (crack-tip opening displacement) values were measured. Figure 4 shows the relationship between the applied load and the clip-gage opening displacement $(\mathrm{P}-\mathrm{Vg})$ for $2.5 \mathrm{~mm}$ thick Laser welded specimens and homogeneous specimen. Specimens with Laser welds very close to the notch (B 2.5 e 1.0) showed brittle fracture, while the homogeneous specimen and another Laser welded specimen (B 2.5 e 1.5) presented ductile fracture. The similar fracture
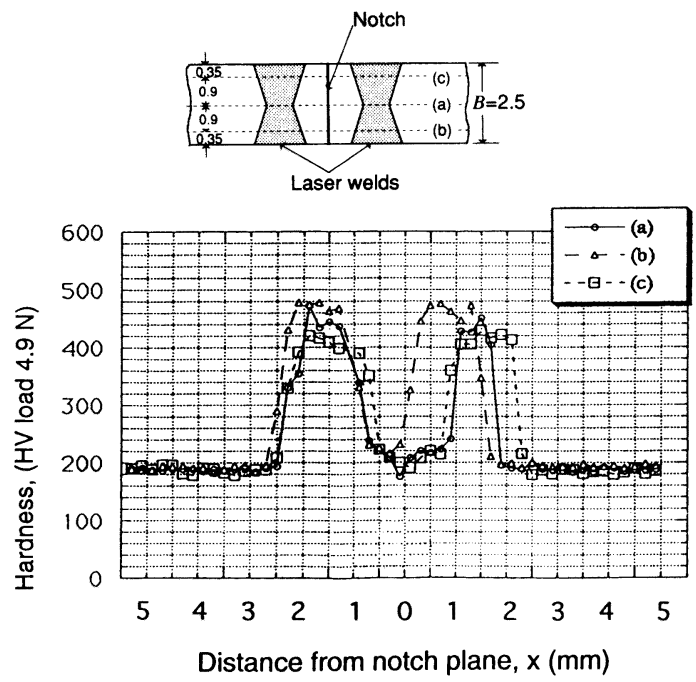

Fig. 2 Hardness distribution at weld cross-section for specimen of $B=2.5 \mathrm{~mm}$.

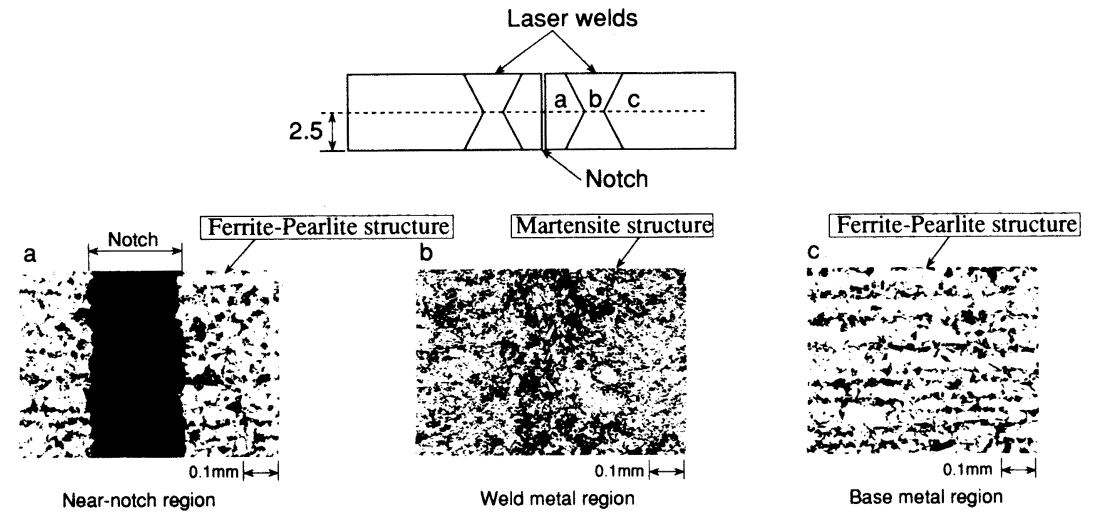

Fig. 3 Microstructures of Laser welded specimen. 


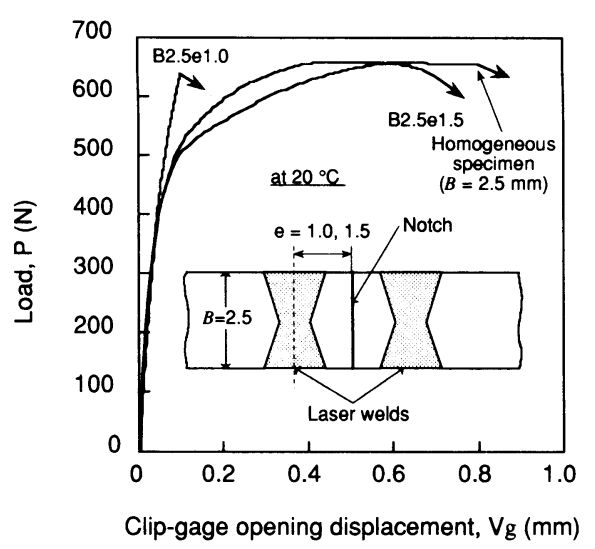

Fig. $4 \quad P-V g$ curves of homogeneous and Laser-welded specimens.

behaviors were observed for $5 \mathrm{~mm}$ thick specimen. The critical values of $K\left(K_{\mathrm{cr}}\right)$ and $\delta\left(\delta_{\mathrm{cr}}\right)$ were calculated at the onset of brittle fracture. In the case of ductile fracture, $K_{\mathrm{cr}}$ and $\delta_{\mathrm{cr}}$ were calculated at the first attainment of the maximum plateau. These values are summarized in Table 2. It should be noted that fracture toughness values for Laser welded specimens which showed brittle fracture were smaller than those for homogeneous full-thickness specimen, although the thickness of Laser welded specimens were very small $(B=2.5,5 \mathrm{~mm})$.

\section{FE-Analysis}

Three dimensional finite element analysis was conducted to investigate the stress/strain behavior at the crack-tip region surrounded by the Laser welds. The FE-analysis pays the attention to factors affecting the degree of plastic constraint. The distance between Laser welds, the width of Laser welds and the shape of Laser welds were considered. For comparison, homogeneous specimens with thicknesses ranging from 2.5 to $100 \mathrm{~mm}$ were also analyzed. The distance $\left(e_{s}\right)$ from Laser welds to the notch plane at the specimen surface was $0.2 \sim 0.6$ and $0.2 \sim 1.2$ for specimen thicknesses $B=2.5$ and $5 \mathrm{~mm}$, respectively. The width of Laser welds was $0.8 \sim 2.6$ and $1.6 \sim 4.6 \mathrm{~mm}$ for $B=2.5$ and $5 \mathrm{~mm}$, respectively. Two weld shapes were applied; the $V$-shape welds $\left(e m>e_{s}\right)$ and the rectangular shape welds $\left(e_{m}=e_{s}\right)$ as shown in Table 3 where, $e_{m}$ is the distance from Laser welds to the notch plane at mid-thickness.

Because of the symmetry, quarter of the specimen was considered. The specimen was modeled with eightnode isoparametric elements provided by the finite element code JNIKE-3 D. Figure 5 shows the example of mesh generation in $\mathrm{FE}$-analysis. Minimum element size at the crack tip was $0.03 \times 0.03 \times 0.25 \mathrm{~mm}$. The mesh division near the crack tip was common to all specimen geometries. Number of layers depends upon specimen
Table 3 Variables used in FE-analysis.

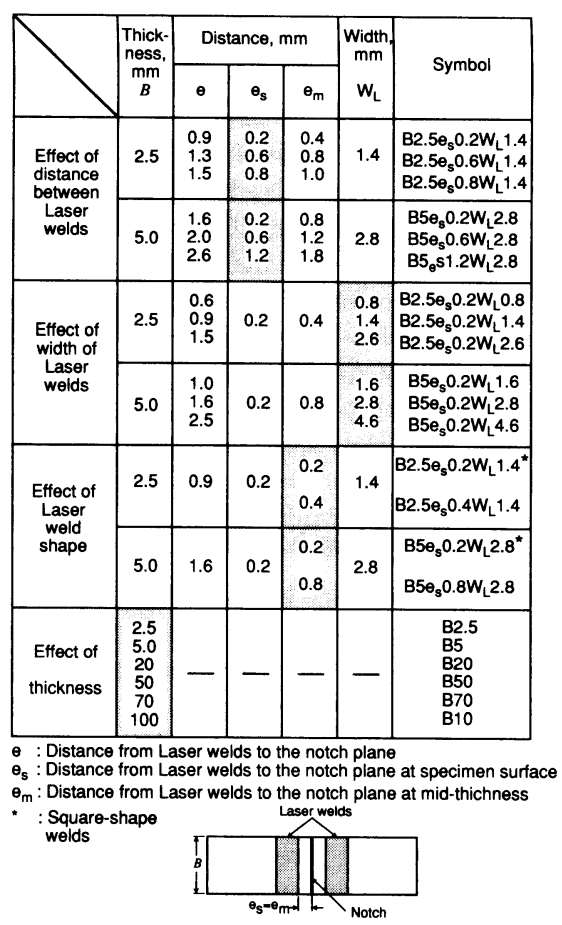

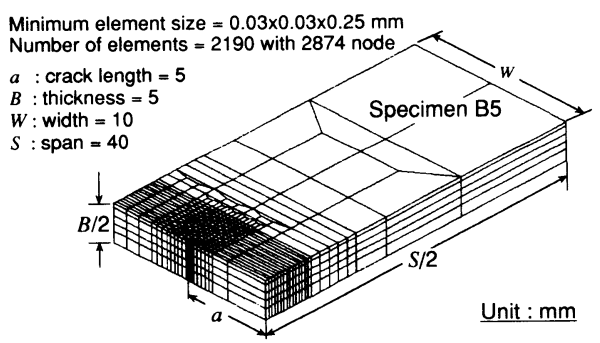

Fig. 5 Example of FE-mesh division used in the analysis.

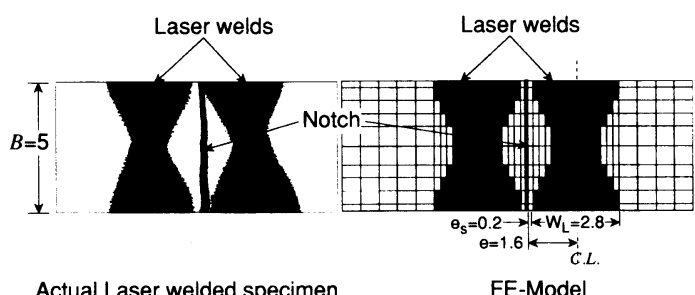

Actual Laser welded specimen

FE-Model

Fig. 6 FE-model for Laser welded specimen used in the analysis.

thickness ; for instance, 3,5 and 7 layers for half-thickness in the case of specimen thickness $B=2.5,5$ and 20 $\mathrm{mm}$, respectively. Figure 6 exhibits the cross ${ }^{-}$section of the $\mathrm{FE}$-model for Laser welded specimen of $B=5 \mathrm{~mm}$ 
and $e=1.5 \mathrm{~mm}$ compared with the actual welded specimen.

The stress-strain relation in the $\mathrm{FE}$-analysis follows the power law :

$$
\bar{\sigma}=\sigma_{Y}\left(1+\bar{\varepsilon}_{p} / \alpha\right)^{n}
$$

where $\bar{\sigma}$ and $\bar{\varepsilon}_{p}$ are the equivalent stress and equivalent plastic strain, respectively, $\sigma_{Y}$ is the yield stress and $n$ and $\alpha$ are material constants. Stress/strain relation of the weld metal was estimated from the hardness ${ }^{12)}$. Figure 7 shows stress- ${ }^{-}$train curves of the base and weld metals used in the FE-analysis.

The $\mathrm{P}-\mathrm{Vg}$ curves for $B=2.5 \mathrm{~mm}$ specimen obtained by experiment and FE-analysis are compared in Fig. 8. Agreement can be seen between the experimental and numerical $\mathrm{P}-\mathrm{Vg}$ curves.

\section{Mis-Matching Effect on Stress Fields}

\section{1 Effect of distance between Laser welds}

Comparison between stress fields of Laser welded specimen and homogeneous specimen was carried out at the CTOD level of $\delta=0.03 \mathrm{~mm}$. This CTOD level corresponds to the average cleavage toughness of the material used.

The influence of the distance $\left(e_{s}\right)$ from Laser welds to the notch plane on the stress distribution is shown in Figs. 9 and 10. The Laser welded specimens of $B=2.5$ $\mathrm{mm}$ with $e_{s}=0.2 \mathrm{~mm}$ revealed a high opening stress over a larger area ahead of the crack tip and through thickness direction as shown in Figs. 9(a) and 10(a). For specimen with $e_{s} \geq 0.6 \mathrm{~mm}$ the stress fields were almost the same as the homogeneous specimen. In the case of $B=5 \mathrm{~mm}$, the highly-stressed regions appeared near the free surface as demonstrated in Fig. 10(b). The $V$ shape of Laser welds was responsible of this phenomenon; the distance $\left(e_{s}\right)$ from Laser welds to the notch plane at surface is smaller than the distance $\left(e_{m}\right)$ at mid -thickness (see Fig. 1).

Highly-stressed regions near the crack tip are

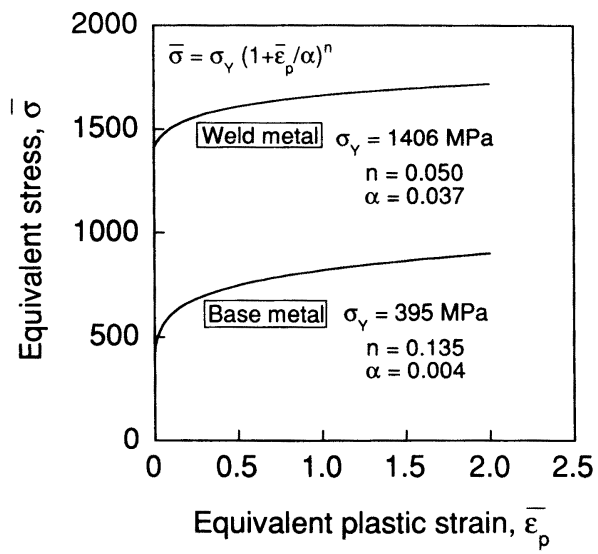

Fig. 7 Stress-strain curves of base metal and weld metal used in the analysis.

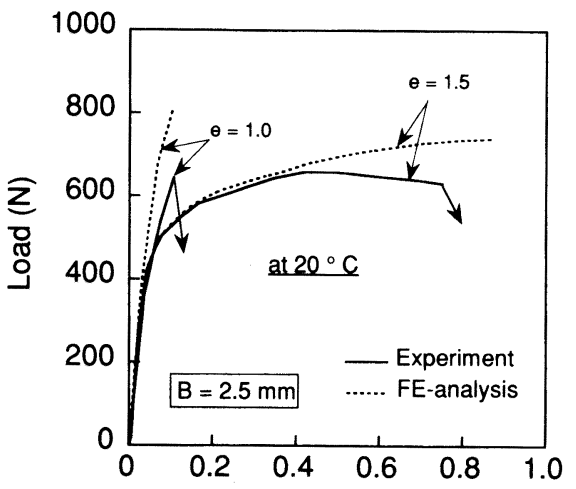

Clip-gage opening displacement, $\mathrm{Vg}(\mathrm{mm})$

Fig. $8 \quad P$ - $V \dot{g}$ curves for Laser welded specimen obtained by experiment and FE-analysis.

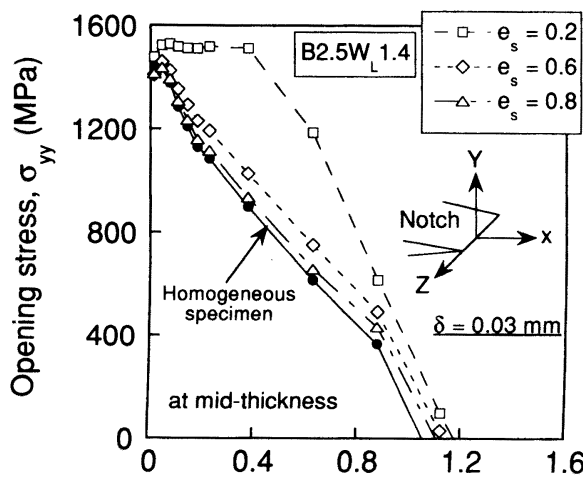

(a)

Distance from crack tip, $x(\mathrm{~mm})$

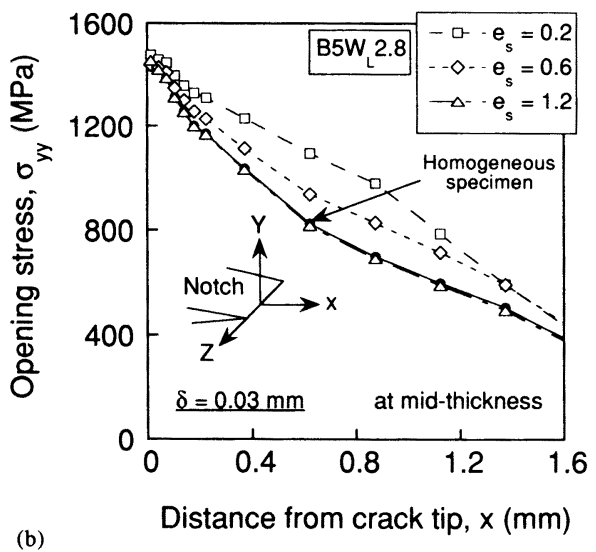

Fig. 9 Effect of $e_{s}$ (distance from Laser welds to notch plane at specimen surface) on opening stress distribution ahead of crack tip for specimens of (a) $B=2.5 \mathrm{~mm}$ and (b) $B=5 \mathrm{~mm}$. 


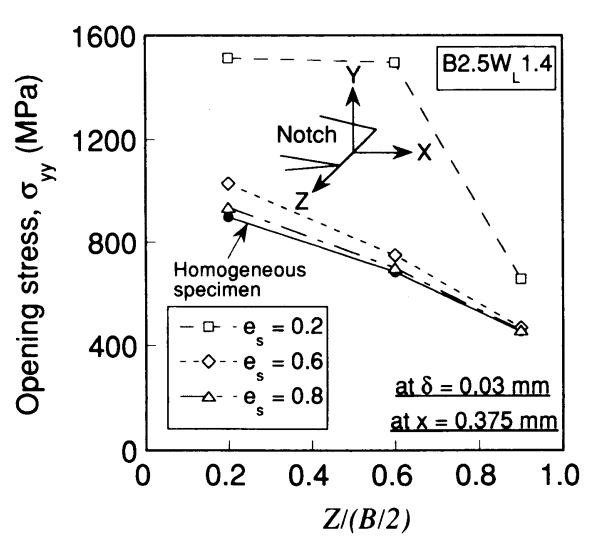

(a)

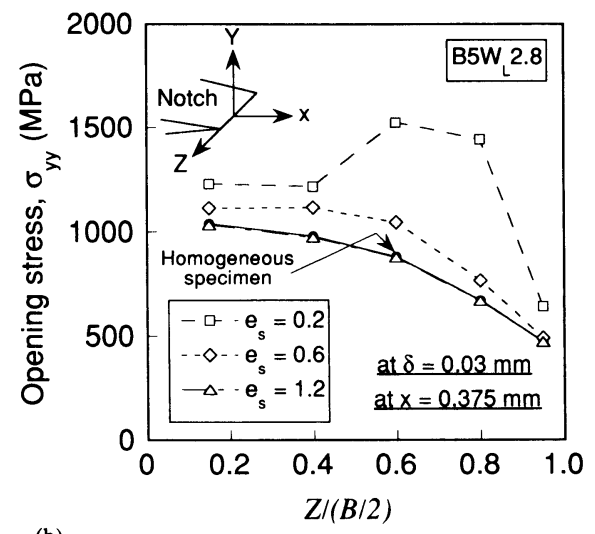

(b)

Fig. 10 Effect of $e_{s}$ (distance from Laser welds to notch plane at specimen surface) on opening stress distribution in thickness direction at $X$ $=0.375 \mathrm{~mm}$ ahead of crack tip of specimen of

(a ) $B=2.5 \mathrm{~mm}$ and (b ) $B=5 \mathrm{~mm}$.

compared in Fig. 11 for specimens of $B=2.5 \mathrm{~mm}$. Contours of the maximum principal stress $\sigma_{1}=3 \sigma_{Y}^{B M}$ are drawn at the same CTOD level $\delta=0.03 \mathrm{~mm}$, where $\sigma_{Y}^{B M}$ is the yield stress of the base metal. Laser welds close

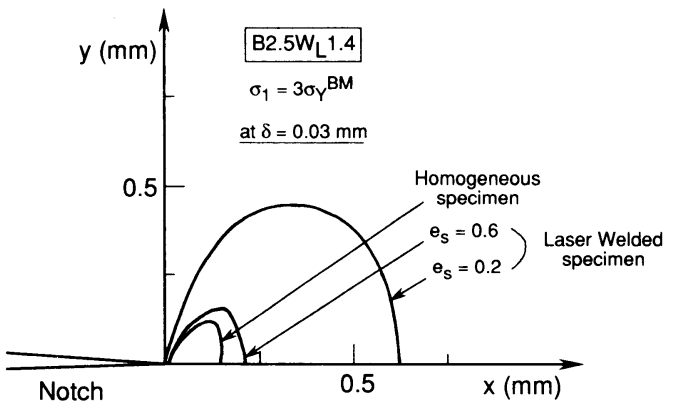

Fig. 11 Contours of the maximum principal stress around crack tip in specimen of $B=2.5 \mathrm{~mm}$ at center of specimen thickness. to the notch $\left(e_{s}=0.2 \mathrm{~mm}\right)$ produces the highly-stressed region to the largest extent. But, in the case of the Laser welded specimen with $e_{s}=0.6 \mathrm{~mm}$ the highlystressed region is considerably smaller, of which size is compatible with the homogeneous specimen.

Figures 9-11 indicate that the stress fields are very sensitive to the distance from Laser welds to the notch plane. Very small shift (from 0.2 to $0.6 \mathrm{~mm}$ ) of the location of Laser welds resulted in a considerable change in the near-tip stress field.

\section{2 Effect of width of Laser welds}

The value of $e_{s}$ was kept constant at $0.2 \mathrm{~mm}$ and the width of Laser welds was changed according to Table 3. It was found that the width $\left(W_{L}\right)$ of Laser welds did not give large influence on stress fields as shown in Fig. 12. The similar results were obtained for specimens with thickness $B=5 \mathrm{~mm}$.

These results indicate that the width of Laser welds applied in experiments is enough to create large plastic constraint by strength mis-matching.

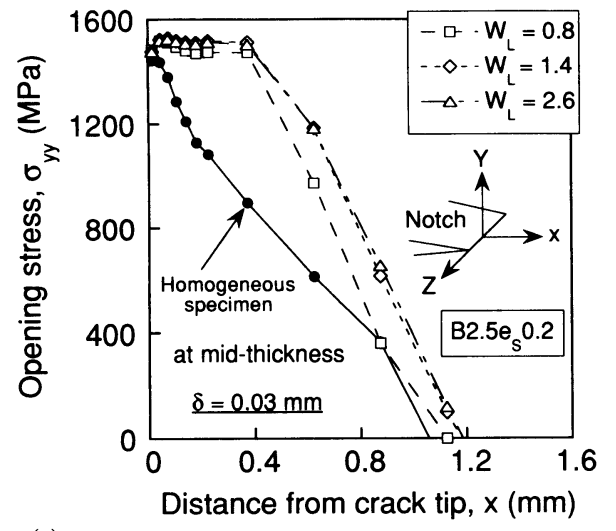

(a)

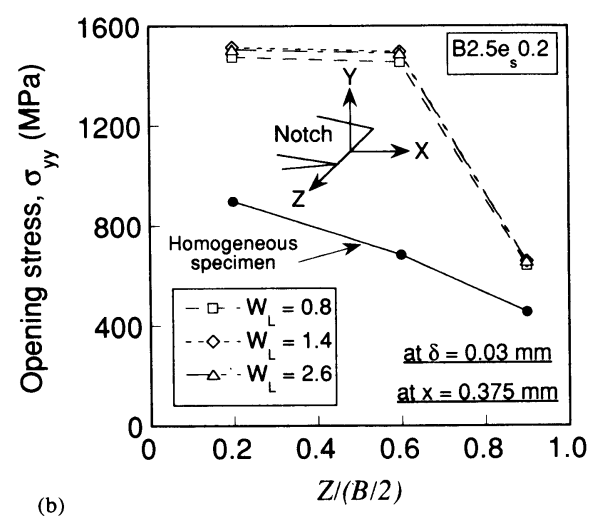

Fig. 12 Effect of $W_{L}$ (width of Laser welds) on opening stress distribution for specimens of $B=2.5 \mathrm{~mm}$ (a) ahead of crack tip and (b) in thickness direction. 


\section{3 Effect of shape of Laser welds}

In order to investigate the influence of the shape of Laser welds, $V$-shape welds $\left(e_{m}>e_{s}\right)$ and rectangular welds $\left(e_{m}=e_{s}\right)$ were considered, where $e_{m}$ and $e_{s}$ were distance from Laser welds to the notch plane at midthickness and that at specimen surface, respectively. Figure 13 shows the influence of the weld shape on the near-tip stress fields. In the case of rectangular welds a marked elevation of the stresses ahead of the crack tip and along crack front was observed. Accordingly, the shape of the weld is also important to realize the constrained state over a large area near crack-tip region.

\section{4 Effect of thickness}

Figure 14 ( a ) exhibits the distributions of the opening stress for homogeneous specimens with various thicknesses. The specimens with thickness $\geq 20 \mathrm{~mm}$ presented almost the same stress distributions. Figure 14(b) compares the stress distributions between the Laser welded specimens and the homogeneous specimens. The Laser welded specimens $(B=2.5,5 \mathrm{~mm})$ present a

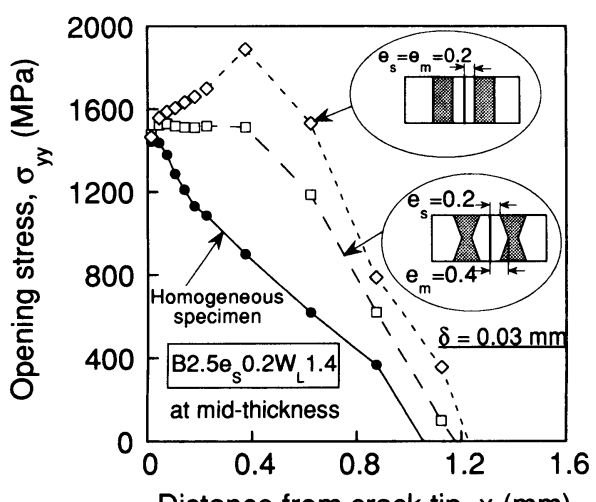

(a)
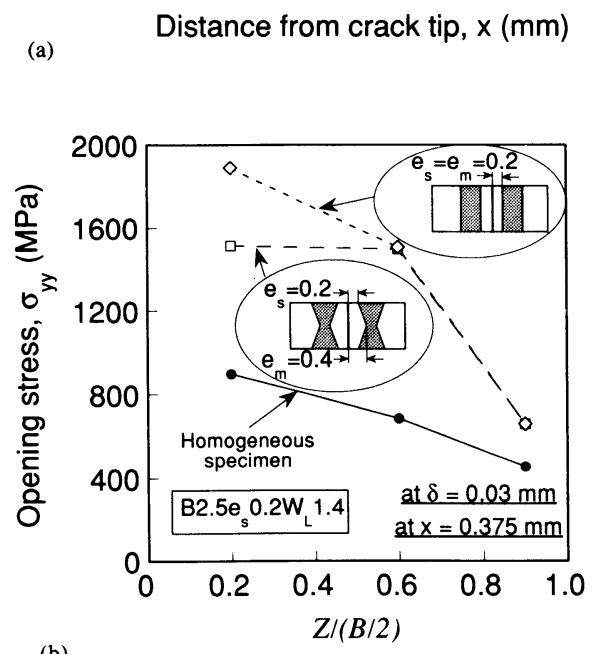

(b)

Fig. 13 Effect of shape of Laser welds on opening stress distribution for specimens of $B=2 \mathrm{~mm}$ (a) ahead of crack tip and (b) in thickness direction. higher stress over larger area than the thick homogeneous specimens. This suggests that lack of thickness constraint could be compensated by the application of very hard zone close to the notch plane.

\section{Mis-Matching Effect on Plastic Constraint}

It is considered that the low fracture resistance of the Laser welded specimens B 2.5 e 1.0 and B 5 e 1.5 is a result of plastic constraint by strength mis-matching. Stress triaxiality in terms of the ratio of hydrostatic stress to Mises stress $\left(\sigma_{H} / \sigma_{M}\right)$ is shown in Fig. 15. Stress triaxiality is apparently enlarged by the application of the Laser welds close enough to the notch. These results indicate that strength mis-matching plays an important role in creating high plastic constraint. This supports the experimental evidence that the Laser welded specimens B 2.5 e 1.0 and B 5 e 1.5 showed a brittle fracture with low fracture toughness.

The influence of controlling factors on the maximum stress triaxiality is summarized in Fig. 16. It is clearly

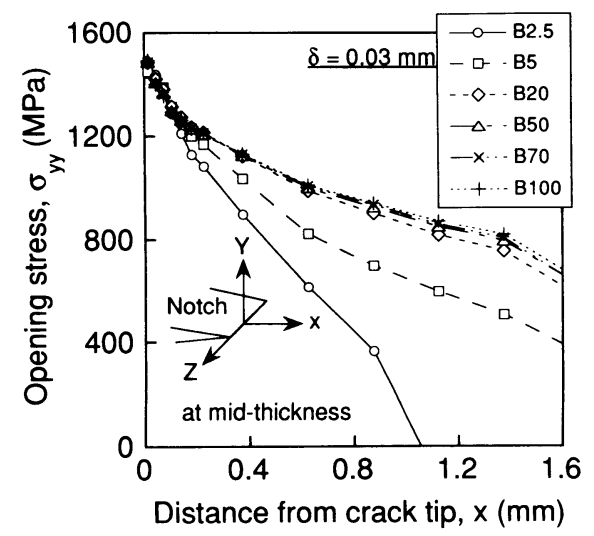

(a)

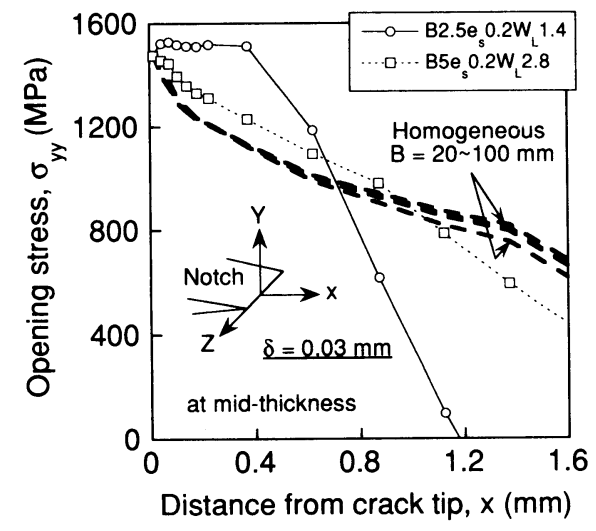

(b)

Fig. 14 Opening stress distribution ahead of crack tip for (a) homogeneous specimens and (b) homogeneous specimens compared with Laser welded specimens. 


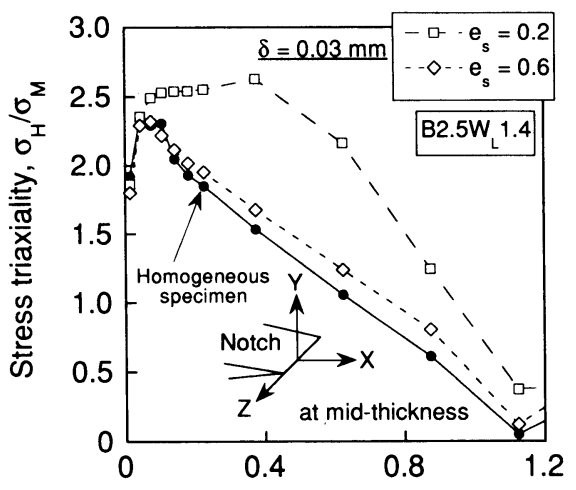

(a)

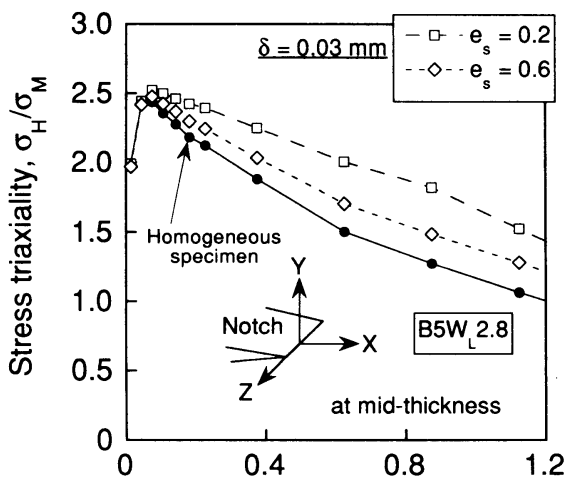

(b)

Fig. 15 Effect of $e_{s}$ (distance from Laser welds to notch plane at specimen surface) on stress triaxiality ahead of crack tip for specimens of (a) $B=2.5$ and (b) $B=5 \mathrm{~mm}$.

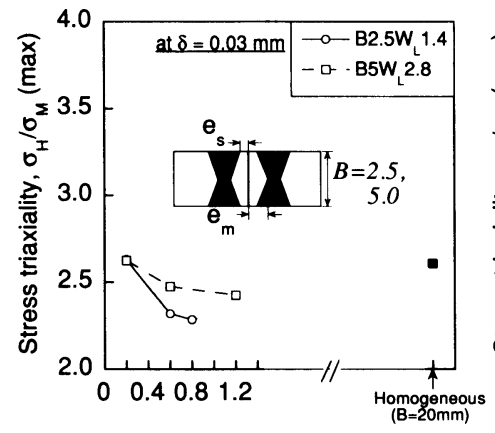

Distance from Laser welds to notch plane at surface, $e_{s}(\mathrm{~mm})$

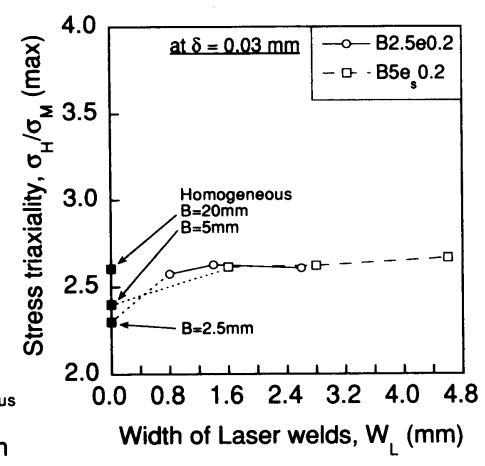

(b)

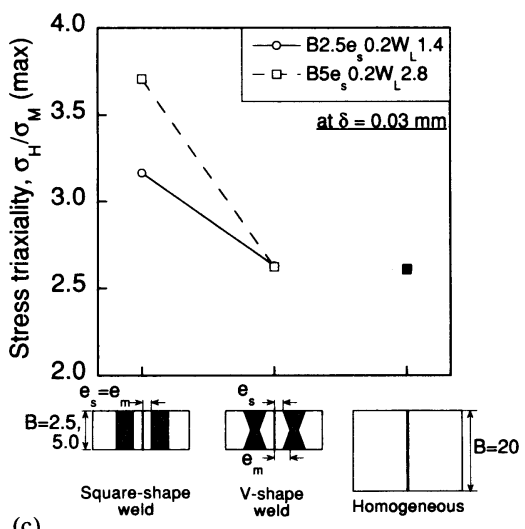

(c)

Fig. 16 Effect of (a) distance from Laser welds to notch plane, (b) width of Laser welds and (c) shape of Laser welds on the maximum stress triaxiality.

shown that the distance from Laser welds to the notch and the weld shape have a marked effect on the plastic constraint. The influence of the width of the weld is minimal.

In this way, it was demonstrated that high constrained state in near-crack tip region can be produced, even for very thin specimen, by locating hard zone near the crack tip. This is attributed to the constraint effect induced by strength mis-matching. Unstable fracture at low load level caused by constraint effect does not directly correspond to the plane strain fracture. However, the present procedure using mis-matching effect was found to be effective to promote brittle fracture for very thin specimen. This could save thickness requirement for the plane strain fracture.
In this study the mis-matching level (the ratio of yield strength of weld metal to that of base metal, $\left.\sigma_{Y}^{W} / \sigma_{Y}^{B M}\right)$ was kept constant. It is expected that the degree of plastic constraint depends on the strength mismatching level as well as the toughness level of the material. Further investigation is now under progress.

\section{Conclusion}

Experimental and analytical investigations on the effect of strength mis-matching on near-crack tip plastic constraint were carried out. Hard zone was made near the notch by Laser welds for very thin specimen (thickness $B=2.5,5 \mathrm{~mm}$ ). Locating Laser welds close to the notch led to brittle fracture at low load level. 3 D FE-analysis figured out that the low fracture resis- 
tance of Laser welded thin specimen is due to the plastic constraint by strength mis-matching. The distance from Laser welds to the notch and the shape of Laser welds gave a great influence on the plastic constraint around the notch tip. The influence of the width of Laser welds was marginal.

The application of hard zone near the notch space of the toughness specimen could save thickness requirement for the attainment of the plane strain fracture. This is attributed to elevation of stresses and enlargement of highly stressed region near the crack tip.

\section{References}

1) S. Aihira and T. Haze, Micro-mechanical analysis of the influence of metallurgical and mechanical inhomogeneity on cleavage fracture initiation, Int. conf. fatigue and corrosion, Fracture mechanics and failure analysis, (19985), 15-26.

2) S. Satoh, Characteristics of deformation and fracture behavior of weldments with mechanical heterogeneity, II W Doc. X-1254-92, Proc. of the workshop on strength mis-matching and its control, Tokyo, (1992), 105-114.

3) M. Toyoda, Significance of mis-matching of steel welds-over/undermatching vs. evenmatch, II W Doc. X-1254-92, Proc. of the workshop on strength mis-matching and its control, Tokyo, (1992), 121 -133 .

4) K. Satoh, M. Toyoda, F. Minami, M. Nakanishi, K. Arimochi and S. Satoh, Effect of mechanical heterogeneity on fracture toughness evaluation of steel welds, Trans. Japan Welding Society, Vol. 16, 2 (1985) , 74-81.

5) C. Ruggieri, F. Minami and M. Toyoda, Effect of strength mis-match on crack tip stress fields of $\mathrm{HAZ}$-notched joints subjected to bending and tension, Jl. Soc. Nav. Arc. Japan, Vol. 174.(1993), 543-549.

6) M. T. Kirk and R. H. Dodds, The influence of weld strength mis-match on crack-tip constraint in single edge notch bend specimens, Int. $\mathrm{Jl}$. Fract., 63 (1993), 297-316.

7) F. Minami, M. Ohata, M. Toyoda, K. Arimochi, S. Suzuki and K. Bessyo, Prediction of specimen geometry effect on fracture resistance of $\mathrm{HAZ}$ notched welds by the local approach, Proc. of the 2nd workshop on constraint effects on structural performance of welded joints, Osaka, (1994), 110.

8) J. C. Newman, C. A. Bigelow and K. N. Shivakumar, Three-dimensional elastic-plastic finiteelement analysis of constraint variations in cracked bodies, Eng. Fract. Mech., vol. 46, 1 (1993), 1-13.

9) Y. Imai and T. Matake, Effect of side groove on the elastic-plastic stress state of fracture toughness specimens-three dimensional finite element analysis, Eng. Fract. Mech., vol. 16, 5 (1982), 659668.

10) M. El-Shennawy, F. Minami and M. Toyoda, Effect of side groove existence on stress/strain behavior of a notched tensile test specimen and its reflection on fracture behavior, Proc. of the 2nd International Conference on Engineering Mathematics and Physics, (ICEMP-94), 27-29 Dec. 1994, Cairo University, Mesr (Egypt), pp. 213-228.

11) ASTM Standard E 399-83, Standard test method for plane-strain fracture toughness of metallic materials, American society of testing and mate rials, (1983).

12) P. Auerkari, On the correction of hardness with tensile and yield strength, VTT Report 416, (1986). 